\title{
Teaching Metrology and Examinology in Chemistry at the University ${ }^{\dagger}$
}

\author{
Ricardo J. N. Bettencourt da Silva \\ Faculdade de Ciências da Universidade de Lisboa, Centro de Química Estrutural, Edifício C8, Campo \\ Grande, 1749-016 Lisboa, Portugal; rjsilva@fc.ul.pt \\ + Presented at the Virtual Eurachem Workshop 2020-“Quality Assurance for Analytical Laboratories in the \\ University Curriculum", 14-15 July 2020; Available online: https://eurachem2020.ro/.
}

Published: 27 September 2020

\begin{abstract}
This communication presents the teaching experience of Ricardo Bettencourt da Silva in the scientific areas of metrology and examinology in chemistry at various universities.
\end{abstract}

Keywords: University course; metrology; examinology; chemistry

\section{Introduction}

Many important socio-economic decisions are supported by the qualitative and/or quantitative chemical analysis of various types of items. Numerous assessments of the individual health, foodstuff safety, product price, process efficiency, etc. are supported by chemical analysis. Therefore, society is continually demanding competent professionals for performing these assessments who, ideally, are capable of moving forward the state-of-art in these areas.

Qualitative and quantitative chemical analyses are designated examinations and measurements in chemistry, respectively [1,2]. The sciences of examinations and measurements and of their applications are defined as examinology and metrology, respectively.

\section{Discussion}

The Universities are expected to contribute to scientific and technological developments by interconnecting graduate and post-graduate teaching with research activities. Their role in societal progress is more relevant when their activities are focused on solving societal problems and challenges.

The interest of the academy in the quality of the analytical information and on their proper interpretation is increasing. This increase has been motivated by requests from the community to produce tools for improving data quality, and the awareness that many data produced in various scientific or technological projects are not comparable or many developed methodologies are not reproducible [3,4]. The poor quality of research data has a significant impact on the cumulative effect of research. It can deviate the community from the investment in unsuccessful research lines because the fruitful solutions were wrongly discharged.

The Chemistry and Biochemistry Department of the Faculty of Sciences of the University of Lisbon (https://ciencias.ulisboa.pt/pt/dqb) has been teaching metrology and examinology in chemistry at the undergraduate, masters, and Ph.D. levels in chemistry and related disciplines. This faculty has also been collaborating in consortiums of various universities for teaching metrology, namely the "International Summer School on Analytical Science, Metrology and Accreditation" (MSC) (https://msc-euromaster.univ-lyon1.fr) and "Erasmus Mundus-European Master in Quality in Analytical Laboratories (EMQAL)" (http://www.emqal.org/). 
This communication presents the teaching experience of Ricardo Bettencourt da Silva in these scientific areas at FCUL, MSC, and EMQAL and is available on Youtube (https://www.youtube.com/watch?v=r_w2szE4PTU).

Conflicts of Interest: The author declares no conflict of interest.

\section{References}

1. Nordin, G.; Dybkaer, R.; Forsum, U.; Fuentes-Arderiu, X.; Pontet, F. Vocabulary on nominal property, examination, and related concepts for clinical laboratory sciences. Pure Appl. Chem. 2018, 90, 913-935.

2. JCGM 200. International Vocabulary of Metrology-Basic and General Concepts and Associated Terms (VIM 3rd edition), 2012. Available online: https://www.bipm.org/utils/common/documents/jcgm/JCGM_ 200_2012.pdf (accessed on 1 July 2020)

3. Baker, M. 1,500 scientists lift the lid on reproducibility -Survey sheds light on the 'crisis' rocking research. Nature 2016, 533, 452-454.

4. Allison, D.B.; Brown, A.W.; George, B.J.; Kaiser, K.A. Reproducibility: A tragedy of errors. Nature 2016, 530, $27-29$.

(c) 2020 by the authors. Licensee MDPI, Basel, Switzerland. This article is an open access article distributed under the terms and conditions of the Creative Commons Attribution (CC BY) license (http://creativecommons.org/licenses/by/4.0/). 